\title{
Metallization Method for Interdigitated Back-Contact Silicon Solar Cells Employing an Insulating Resin Layer and a Ti/Ag/Cu Metal Stack
}

\author{
Ning Song ${ }^{(\mathbb{D}}$, Udo Römer, Angus Gentle, Sean Lim, Zhongtian Li, Pei-Chieh Hsiao ${ }^{\mathbb{D}}$, Bin Gong, Xueling Zhang, \\ Pierre Verlinden, and Alison Lennon
}

\begin{abstract}
Interdigitated back-contact (IBC) silicon (Si) solar cells are attracting increased attention due to the potential of higher efficiency that comes from eliminating front-surface shading. However, as sources of recombination loss continue to be reduced due to improved processing and use of high-quality n-type wafers, parasitic absorption in the rear metal can limit cell performance. This paper reports experimental and simulation results that identify the optical advantages of an IBC metallization method, which employs a novolac resin layer to enhance the insulation of the cell from a metal electrode comprising a sputtered Ti/Ag metal stack and plated $\mathrm{Cu}$. The polymer layer can electrically decouple the metal geometry from the doping geometry and also helps to reduce the parasitic absorption at the cell rear surface by increasing the distance between the metal and $\mathrm{Si}$ absorber. The optical properties of the Ti/Ag stacks formed over the novolac resin were comparable to those with an Ag reflector; however, the $\mathrm{Ti} / \mathrm{Ag}$ reflector offered the additional benefit of contact resistivity of $<1 \mathrm{~m} \Omega \cdot \mathrm{cm}^{2}$ to both the $\mathbf{n}^{+}$and $\mathbf{p}^{+}$Si regions of the diffused IBC cells.
\end{abstract}

Index Terms-Interdigitated back contacts, metallization, optical performance, polymer, silicon $(\mathbf{S i})$ solar cells, silver, titanium.

\section{INTRODUCTION}

$\mathbf{I}$ NTERDIGITATED back-contact (IBC) silicon (Si) solar cells have drawn increasing attention as a path to higher

Manuscript received January 30, 2018; revised March 28, 2018; accepted April 5, 2018. This work was supported by the Australian Government through the Australian Renewable Energy Agency. (Corresponding author: Ning Song.)

N. Song, U. Römer, Z. Li, P.-C. Hsiao, and A. Lennon are with the School of Photovoltaic and Renewable Energy Engineering, University of New South Wales Sydney, Sydney, NSW 2052, Australia (e-mail: n.song@unsw.edu.au; u.romer@unsw.edu.au; zhongtian.pv@gmail.com; p.hsiao@unsw.edu.au; a.lennon@unsw.edu.au).

A. Gentle is with the School of Mathematical and Physical Sciences, University of Technology Sydney, Sydney, NSW 2007, Australia (e-mail: angus. gentle@uts.edu.au).

S. Lim is with the Electron Microscope Unit, Mark Wainwright Analytical Centre, University of New South Wales Sydney, Sydney, NSW 2052, Australia (e-mail: sean.lim@unsw.edu.au).

B. Gong is with the Solid State and Elemental Analysis Unit, Mark Wainwrght Analytical Centre, University of New South Wales Sydney, Sydney, NSW 2052, Australia (e-mail: b.gong@unsw.edu.au).

X. Zhang and P. Verlinden are with the State Key Lab of PV Science and Technology, Trina Solar Limited, Changzhou 213031, China (e-mail: xueling. zhang@ trinasolar.com; pjverlinden@ieee.org).

This paper has supplementary downloadable material available at http://ieeexplore.ieee.org.

Color versions of one or more of the figures in this paper are available online at http://ieeexplore.ieee.org.

Digital Object Identifier 10.1109/JPHOTOV.2018.2825465 solar energy conversion efficiencies with cell efficiencies exceeding $26 \%$ having been reported [1]. These cells offer the advantages of

1) no front-surface metal shading;

2) greater (rear) metal coverage leading to lower resistive losses;

3) reduced front-surface recombination;

4) simpler, more robust cell-interconnecting methods.

Continued increases in cell efficiency require an analysis of where losses are occurring in cells. Smith et al. reported that rear optical losses were the largest source of loss in Sunpower's $>25.0 \%$ IBC cells, this loss contributing $\sim 4 \%$ to the total power loss of a $25.0 \%$ efficient cell [2]. In an analysis of the losses for a $26.3 \%$ efficient amorphous Si heterojunction IBC cell, Yoshikawa et al. attributed $\sim 1.6 \%$ of the $3.4 \%$ loss in shortcircuit current density $J_{S C}$ compared with the theoretical limit, to non-Lambertian light trapping and parasitic absorption in the rear amorphous Si and metal electrodes [1]. Therefore, identifying metal contacting structures, for which parasitic absorption can be reduced, will provide a path to further increases in IBC cell efficiencies.

We have previously reported a metallization scheme that incorporates a novolac polymer layer placed between the rear passivation dielectric and the metal electrodes of IBC solar cells [3]-[5]. This layer can electrically decouple the metal electrode geometry from the Si doping geometry through improved insulation [6]-[9]. It can also act to reduce parasitic absorption in the metal electrodes by increasing the distance between the metal and the Si absorber [4], [10]-[12]. A similar resin material was used as a rear-surface insulating layer on CSG Solar modules [13]. At the time of their production, these thin-film Si modules outperformed some screen-printed crystalline Si modules and a cadmium indium selenide thin-film module. This suggests that retaining the novolac resin as part of the final module does not impact durability [13].

Additionally, the novolac polymer can be patterned using an inkjet printing process that can result in point openings of diameters $\sim 20 \mu \mathrm{m}$ [14], [15]. This can make possible reduced contact fractions and hence reduced contact recombination provided that low contact resistances to both the $\mathrm{n}^{+}$and $\mathrm{p}^{+} \mathrm{Si}$ regions of diffused IBC cells [16] can be achieved. Engineering of an optimized metal electrode that can provide both a high reflectivity and low contact resistance to both $\mathrm{n}^{+}$and $\mathrm{p}^{+}$regions can 


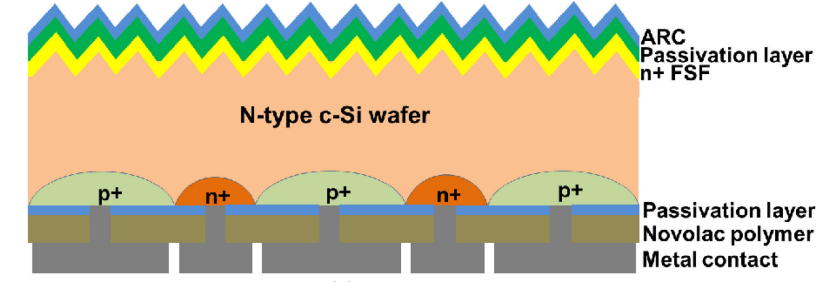

(a)

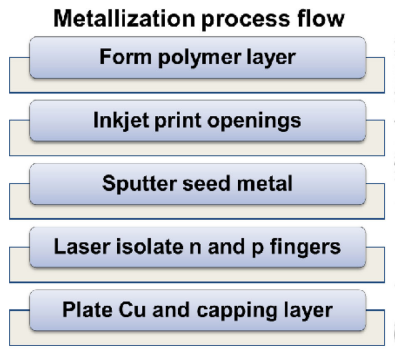

(b)

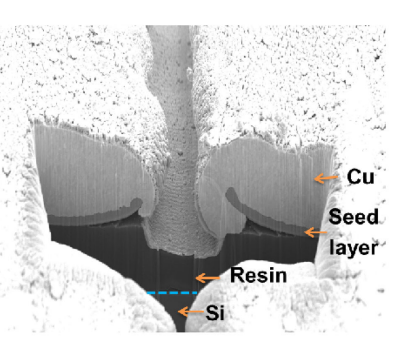

(c)
Fig. 1. (a) Schematic depicting the components of the IBC metallization scheme used in this study. (b) Process flow for forming the rear metallization structure. (c) Cross-sectional scanning electron microscope image showing the components of the rear metallization stack at an isolation line between two $\mathrm{Cu}$-plated electrodes. The SEM image was recorded at a tilt angle of $45^{\circ}$ after focused ion beam milling through the rear contact. The seed layer has "curled" up slightly at the edges of the isolation line, presumably, due to stress that may have been induced by laser ablation and/or $\mathrm{Cu}$ plating.

provide even further advantages in allowing improved light trapping and reduced doping of both the emitter and back-surface field regions of the cell.

In this paper, we report the results of investigations into the use of a Ti/Ag stack formed over a novolac polymer insulating layer on the rear surface of IBC cells as a contact metal and seed layer for $\mathrm{Cu}$ plating of the rear electrodes. Titanium can be used to form low-resistance ohmic contacts to both p-type and n-type Si [17]; however, Ag can provide superior rear reflection properties. Consequently, metal stacks containing thin layers of $\mathrm{Ti}$ and $\mathrm{Ag}$ can provide a compromise between low contact resistance and reduced parasitic absorption in the rear metal electrode. $\mathrm{Ti} / \mathrm{Pd} / \mathrm{Ag}$ metal contacting stacks were used in early solar cells for space applications [18]-[20], with Pd being used to prevent undesirable reactions between $\mathrm{Ti}$ and $\mathrm{Ag}$. However, Ti/Ag metal stacks, which eliminate the need to use expensive $\mathrm{Pd}$, have also been shown to not result in contact degradation in Si solar cells [20]. Couderc et al. [21] reported that a Ti/Ag stack layer with only a $5 \mathrm{~nm}$ Ti resulted in reduced parasitic absorption and higher reflectance at the Si-metal interface compared with a metal stack comprising Ti $(50 \mathrm{~nm}) / \mathrm{Pd}(50 \mathrm{~nm}) / \mathrm{Ag}$ stack. These metal contacting studies suggest that $\mathrm{Ti} / \mathrm{Ag}$ can provide an effective contacting/seed layer for $\mathrm{Cu}$-plated electrodes, provided sufficient adhesion can be achieved between the Ti and Ag layers [20].

Fig. 1(a) shows a schematic of the IBC metallization scheme proposed in this study [5]. The process flow for fabricating the rear contact structure, which uses the above-described inkjet patterning method, is shown in Fig. 1(b) [14], [15]. Fig. 1(c) shows a cross-sectional scanning electron microscope (SEM) image through an isolation line between two $\mathrm{Cu}$ rear electrodes that have been plated to the sputtered Ti/Ag seed layer.

\section{EXPERIMENTAL}

Test structures were fabricated for contact resistance and optical measurements as follows. Metal layers comprising $200 \mathrm{~nm} \mathrm{Ti} ; 200 \mathrm{~nm} \mathrm{Ag;} \mathrm{a} 2 \mathrm{~nm} \mathrm{Ti} / 200 \mathrm{~nm} \mathrm{Ag} \mathrm{metal} \mathrm{stack}$ were sputtered on the rear surfaces of each of

1) IBC precursors with $4-\mu$ m-thick spin-coated novolac resin (with resin);

2) IBC cell precursors (without resin);

3) IBC cell precursors with the rear $\mathrm{Si}$ nitride $\left(\mathrm{SiN}_{x}\right)$ dielectric layers etched by immersion in $1 \%$ hydrofluoric acid (Si).

The Ti/Ag stacks were sputtered without breaking the vacuum to ensure no contamination occurred at the surface that could impact the adhesion of the Ag to the Ti [15]. The precursors with resin were baked at $160{ }^{\circ} \mathrm{C}$ for $10 \mathrm{~min}$ before metal sputtering to remove residual solvent and ensure that the resin was as stable as possible. This heat treatment can also retain the excellent electrical insulation properties of resin [4].

Transmission line method (TLM) measurements of contact resistivity, $\rho_{\mathrm{c}}$, were performed for each of the three metal layers on the $15 \Omega / \square$ P-doped and $75 \Omega / \square$ B-doped Si surfaces of the IBC cell precursors. The front-surface reflectance of the test structures in the 900-1200 nm wavelength range was measured using a Perkin Elmer Lambda 1050 UV-Vis-NIR Spectrophotometer. The measurements were used to characterize the rear reflection properties of the three rear dielectric/metal stacks. The contact resistance and reflectance were both measured again after annealing at $160{ }^{\circ} \mathrm{C}$ for $10 \mathrm{~min}$ on a hot plate. The latter temperature was selected to minimize changes of the resin [4].

The surface morphology of the metal films was studied by atomic force microscope (AFM) (Bruker Dimension ICON SPM). The microstructure of the metals and interfaces was investigated using high-resolution transmission electron microscope (TEM) and energy-dispersive X-ray spectroscopy (JEOL JEM-ARM200f). X-ray photoelectron spectroscopy (XPS) (ESCALAB250Xi) was used to determine the elemental profiles and chemical states of the metals in the metal stacks before and after annealing.

\section{OPTICAL SimULATIONS}

In order to quantify the influence of the different metal stacks on the rear optical performance of IBC cells, three-dimensional ray-tracing simulations were performed using the module ray tracer from PV Lighthouse Pty Ltd [22]. Following the approach of McIntosh et al. [23], the reflectivity and transmissivity of textured solar cell precursors without antireflection coatings and passivation layers were first measured and then ray-tracing simulations were performed to determine the characteristic angle of the front-surface random-textured pyramids resulting from the alkaline texturing process. Using this characteristic angle, the measured and simulated reflectances of the IBC cell precursors with dielectric layers prior to resin application and metallization were used to determine the thicknesses of the antireflection 
TABLE I

MEASURED CONTACT RESISTIVITY ON BORON AND PHOSPHORUS-DOPED SURFACES

\begin{tabular}{ccc}
\hline \hline & \multicolumn{2}{c}{ Phosphorus doped } \\
\cline { 2 - 3 } & Before annealing & After annealing \\
$\mathrm{Ti} / \mathrm{Ag}$ & $\rho_{c}\left(\mathrm{~m} \Omega \cdot \mathrm{cm}^{2}\right)$ & $\rho_{c}\left(\mathrm{~m} \Omega \cdot \mathrm{cm}^{2}\right)$ \\
$\mathrm{Ti}$ & $1.1 \pm 0.6$ & $0.71 \pm 0.19$ \\
$\mathrm{Ag}$ & $2.2 \pm 1.9$ & $0.54 \pm 0.01$ \\
& $0.15 \pm 0.04$ & $0.28 \pm 0.12$ \\
\cline { 2 - 3 } & \multicolumn{3}{c}{ Boron doped } \\
$\mathrm{Ti} / \mathrm{Ag}$ & Before annealing & After annealing \\
$\mathrm{Ti}$ & $\rho_{c}\left(\mathrm{~m} \Omega \cdot \mathrm{cm}^{2}\right)$ & $\rho_{c}\left(\mathrm{~m} \Omega \cdot \mathrm{cm}^{2}\right)$ \\
$\mathrm{Ag}$ & $6.8 \pm 3.0$ & $0.20 \pm 0.14$ \\
& $94 \pm 27$ & $0.55 \pm 0.12$ \\
& $73 \pm 39$ & $19 \pm 11$ \\
\hline
\end{tabular}

layer. The simulated and measured reflectance at long wavelengths was also used to determine the Lambertian fraction of the rear surface.

In order to account for free carrier absorption (FCA) in the rear-surface $\mathrm{n}^{+}$and $\mathrm{p}^{+}$regions in the simulations, the doping profiles of the regions were determined using electrochemical capacitance voltage measurements and the model of Baker-Finch et al. [24] was used to calculate the FCA of both regions for each wavelength. The contribution of FCA was then accounted for in the simulations by including a $500 \mathrm{~nm}$ layer on the solar cell rear surface with the refractive index of $\mathrm{Si}$ (obtained from Schinke et al. [25]) and a wavelength-dependent extinction coefficient that resulted in the same calculated FCA.

Simulations of front-surface reflectance were then performed for the different rear surfaces (with resin, without resin, and $\mathrm{Si}$ ) using the above-described input parameters and measured optical constants (refractive index, $n$, and extinction coefficient, $k$ ) for each metal layer and resin, which can be found in Table SI in the Supplemental file. All the simulations (with resin) assumed that the thickness of the novolac resin was $4 \mu \mathrm{m}$.

\section{RESUlTS AND DISCUSSION}

\section{A. Contact Resistivity}

The values of $\rho_{c}$, obtained from the TLM measurements, before and after annealing for each of the metal stacks are shown in Table I. After annealing, $\rho_{c}$ values $<1 \mathrm{~m} \Omega \cdot \mathrm{cm}^{2}$ were obtained for the $\mathrm{n}^{+}$surfaces with each of the metal contact layers with the lowest $\rho_{c}$ of $0.28 \pm 0.12 \mathrm{~m} \Omega \cdot \mathrm{cm}^{2}$ being achieved for the $\mathrm{Ag}$ layer. However, it was more difficult to achieve a low $\rho_{c}$ for the $\mathrm{p}^{+}$surface using $\mathrm{Ag}$, and values $<1 \mathrm{~m} \Omega \cdot \mathrm{cm}^{2}$ (target value for the cell design) were only possible using the $\mathrm{Ti}$ and $\mathrm{Ti} / \mathrm{Ag}$ stacks after annealing. Annealing had the most impact for the layers containing Ti suggesting that interface changes between $\mathrm{Ti}$ and $\mathrm{Si}$ that reduce the contact resistivity had occurred with annealing (e.g., formation of a Ti silicide [17]).

\section{B. Reflectance}

In this section, the reflectance values of the different test structures are compared at high wavelengths. As the absorption of $\mathrm{Si}$ is very low at $1200 \mathrm{~nm}$, it is assumed that higher reflection

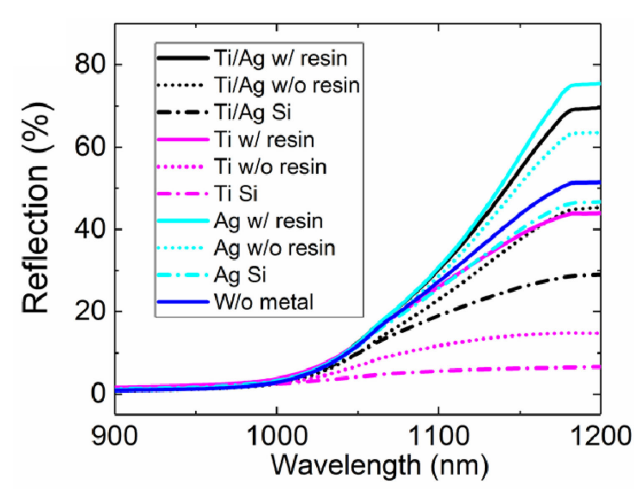

(a)

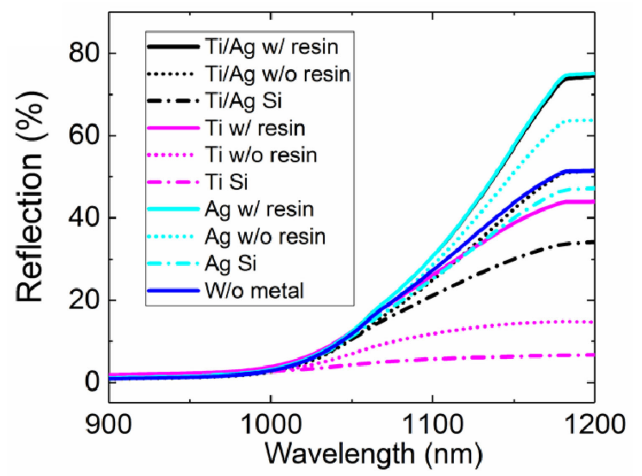

(b)

Fig. 2. Front-surface reflectance of different rear-surface dielectric/metal stacks Ti/Ag metal stacks. (a) Before annealing. (b) After annealing. Without metal refers to an IBC cell precursor without any metal and the other legend labels are as defined in Section II.

at this wavelength can be used as a measure of reduced parasitic absorption in the other layers. We assumed that our different rear metallization layouts, especially the incorporation of the Novolac layer did not significantly alter the scattering, which otherwise could also lead to changed pathlengths of the reflected light in the $\mathrm{Si}$, and thus to changed band-to-band absorption in the Si.

The front total reflectances of the different test structures for the wavelength range 900-1200 nm are shown in Fig. 2. With the incorporation of the novolac resin layer, which has low $n$ and $k$ values [4], the reflectances increased for all the different metal layers due to the increased displacement of the metal from the Si absorber [see Fig. 2(a)]. The test structures with Ag resulted in the highest reflectance for each precursor type. Titanium is a poorer reflector of light entrant from Si than Ag [21]. The Ti/Ag stack metal layer improved the optical reflectance at the rear side compared with $200 \mathrm{~nm}$ Ti for all the cell precursors.

The front-surface reflectance of the test structures with only $\mathrm{Ti}$ or only $\mathrm{Ag}$ was unchanged after annealing; however, it increased by $5.0 \%-6.1 \%$ at $1200 \mathrm{~nm}$ for the test structures with the Ti/Ag stack [see Fig. 2(a)]. This suggests that annealing of the Ti/Ag stack results in changes which reduce parasitic absorption in the metal stack that is evident after deposition. In fact, there is no difference in the front-surface reflectance of the annealed test structures with novolac resin and a Ti or Ag contact metal layer. Also, the optical constants of $\mathrm{Ti}$ and $\mathrm{Ag}$ were found to be 


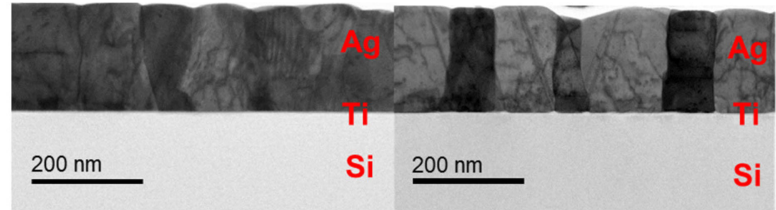

(a)

(b)

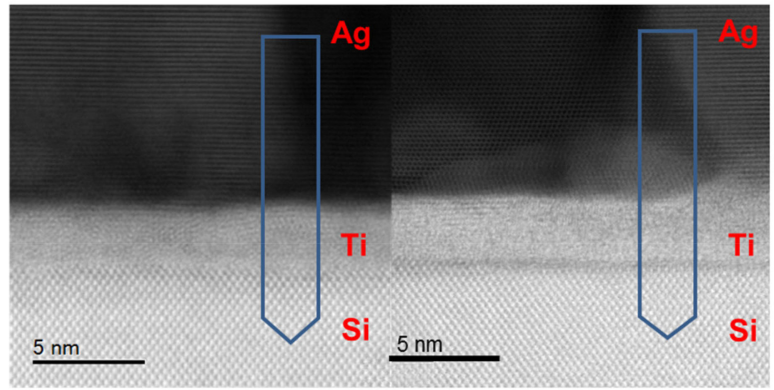

(c)

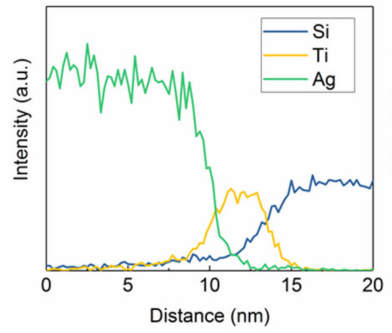

(e) (d)

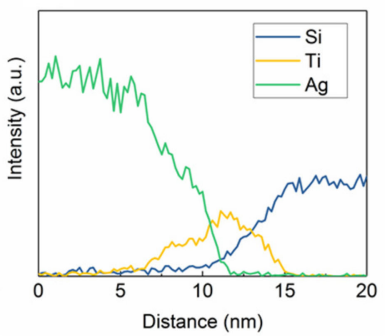

(f)

Fig. 3. Cross-sectional bright-field TEM images of the Ti/Ag interface with $\mathrm{Si}$ (a) before annealing and (b) after annealing showing the increased $\mathrm{Ag}$ grain sizes with annealing; (c) and (d) are high-resolution bright-field TEM images recorded from the $\mathrm{Si}<110>$ zone axis before and after annealing, respectively; and (e) and (f) are EDS line scans of the areas in the blue arrows in (c) and (d) that show diffusion of $\mathrm{Ti}$ into both $\mathrm{Si}$ and $\mathrm{Ag}$ with annealing.

unchanged (by ellipsometry) after the annealing on the hot plate. Therefore, we assume the annealing did not make changes in the resin layer. This is advantageous, as annealing therefore acts to improve the optical performance of the Ti/Ag contacting stack such that it behaves like an $\mathrm{Ag}$ reflector, but with the benefit of low $\left(<1 \mathrm{~m} \Omega \cdot \mathrm{cm}^{2}\right)$ contact resistivity to both the $\mathrm{n}^{+}$and $\mathrm{p}^{+}$ regions.

\section{Interface Microstructure Analysis}

Microstructural analyses were performed to explore the underlying mechanisms for the resistive and optical changes reported above. AFM images (not shown) suggest that the grain sizes of the as-sputtered $\mathrm{Ag}$ films were relatively homogenous but grew unevenly with annealing. The root-mean-square roughness and the $Z$ range detected from the AFM analysis increased from 4.4 to $5.2 \mathrm{~nm}$ and 35.3 to $53.2 \mathrm{~nm}$, respectively. Grain size changes with annealing were not observed with the sputtered $\mathrm{Ti}$ films.

Fig. 3 shows cross-sectional TEM images of sputtered Ti/Ag stacks on a $\mathrm{p}^{+} \mathrm{Si}$ substrate before and after annealing. The nonannealed $\mathrm{Ag}$ displays a columnar structure with a grain size of $\sim 100 \mathrm{~nm}$ [see Fig. 3(a)]; however, after annealing the Ag grains partially grew larger [see Fig. 3(b)], which is consistent with the nonuniform grain growth that was evident from the

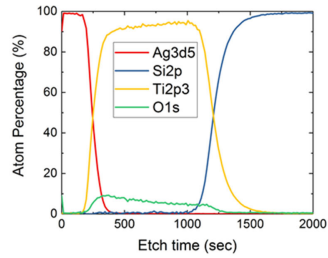

(a)

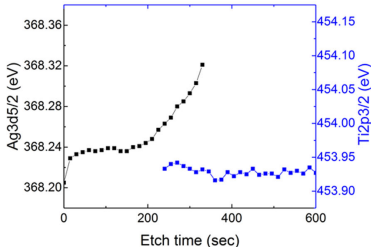

(c)

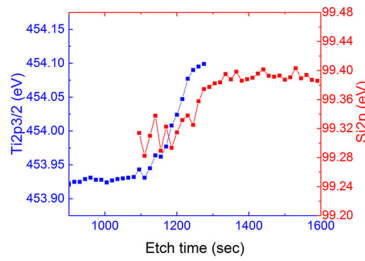

(e)

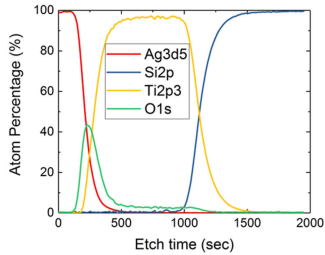

(b)

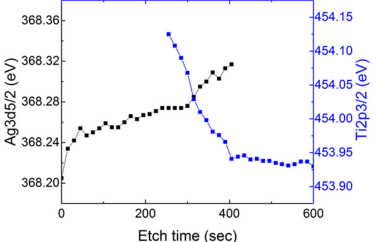

(d)

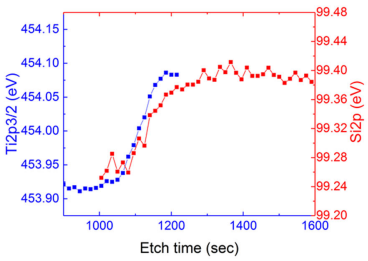

(f)
Fig. 4. XPS depth profiles of the cross section of Ti/Ag on $\mathrm{Si}$ (a) before and (b) after annealing. Binding energy of $\mathrm{Ag} 3 \mathrm{~d} 5 / 2$ and $\mathrm{Ti} 2 \mathrm{p} 3 / 2$ of $\mathrm{Ti} / \mathrm{Ag}$ on $\mathrm{Si}$ (c) before and (d) after annealing. Binding energy of Ti 2p3/2 and $\mathrm{Si} 2 \mathrm{p}$ of Ti/Ag on $\mathrm{Si}(\mathrm{e})$ before and (f) after annealing.

AFM analysis. The interface of $\mathrm{Ti}$ and $\mathrm{Ag}$ became rougher close to the Ag grain boundaries after annealing [see Fig. 3(b)]. The high-resolution TEM images in Fig. 3(c) and (d) show that the sputtered Ti was amorphous and that the interface between the $\mathrm{Ti}$ and $\mathrm{Si}$ became sharper after annealing. The dark contrast at this interface may arise from the formation of a thin TiSi which can contribute to the reduced $\rho_{c}$ after annealing [17]. The EDS line scans in Fig. 3(e) and (f) confirm that the Ti has diffused both into the $\mathrm{Ag}$ and the $\mathrm{Si}$ with annealing.

In order to study the elemental bonding at the $\mathrm{Ti} / \mathrm{Si}$ and $\mathrm{Ag} / \mathrm{Ti}$ interfaces, a Ti/Ag stack comprising of $50 \mathrm{~nm}$ Ti and $50 \mathrm{~nm} \mathrm{Ag}$ was sputtered on a $\mathrm{p}^{+} \mathrm{Si}$ substrate. The compositional depth profiles of $\mathrm{Ti}, \mathrm{Ag}, \mathrm{O}$, and $\mathrm{Si}$ before and after annealing are shown in Fig. 4(a) and (b), respectively. Annealing resulted in the atomic $\%$ of $\mathrm{O}$ in the Ti layer being reduced from $\sim 6.3 \%$ to $2.9 \%$, and the formation of an $\mathrm{O}$ peak at the interface of the $\mathrm{Ti}$ and $\mathrm{Ag}$, with the atomic $\%$ of $\mathrm{O}$ in this region increasing from $10 \%$ to $40 \%$. In Fig. 4(d), the Ti 2p3/2 core level also increased at the Ti/Ag interface after annealing (453.93-454.13 eV), providing further evidence for the formation of $\mathrm{TiO}_{2-x}$ at the interface. The XPS results suggest that at least one source of the $\mathrm{O}$ for the interfacial $\mathrm{TiO}_{2-x}$ is $\mathrm{O}$ that may be incorporated in the $\mathrm{Ti}$ during sputtering.

Fig. 4(e) and (f) provides further evidence for the formation of a TiSi at the Ti and Si interface. The binding energy of the Ti $2 \mathrm{p} 3 / 2$ core level increases slightly at the Si interface indicating some binding of $\mathrm{Ti}$ and $\mathrm{Si}$. There is also a slightly reduced O signal [see Fig. 4(b)] which may contribute to the reduced contact resistance with annealing. Titanium is known to have a high affinity to $\mathrm{O}$ and has been reported to reduce native oxides 


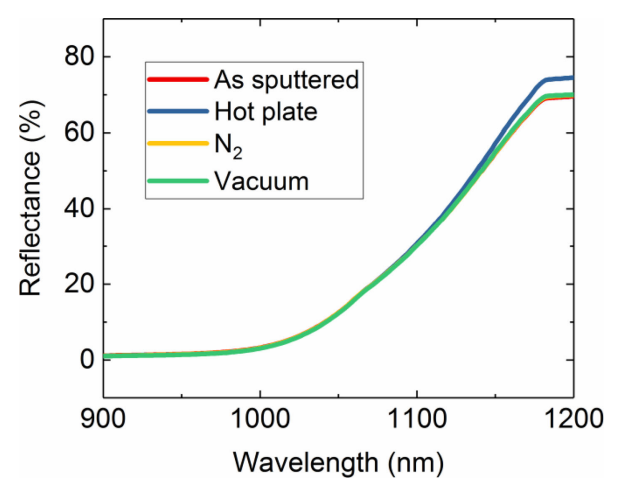

Fig. 5. Front-surface reflectance of Ti/Ag metal stack with novolac resin before and after annealing in different ambients.

on Si during subsequent annealing steps and reacts with $\mathrm{Si}$ to form Ti silicides resulting in low contact resistance [17], [26].

To investigate the role of annealing ambient in the abovementioned interface changes, the front-surface reflectance was measured after hot-plate annealing in air, rapid thermal processing annealing in an $\mathrm{N}_{2}$ ambient, and annealing in a sputtering chamber with high vacuum $\left(10^{-7}\right.$ Torr $)$ for 10 min [see Fig. 5]. While there was only minimal change in the reflectance at $1200 \mathrm{~nm}$ for both $\mathrm{N}_{2}$ and vacuum annealing, a larger increase $(69.5 \%-74.5 \%)$ was observed for hot-plate annealing in air. This suggests that $\mathrm{O}_{2}$ incorporation during annealing is contributing to the improved optical performance of the Ti/Ag stack layer. It is proposed that $\mathrm{O}_{2}$ from the air diffused along $\mathrm{Ag}$ grain boundaries during annealing to react with $\mathrm{Ti}$ and form transparent $\mathrm{TiO}_{2-x}$ [27]. The partial diffusion of the $\mathrm{Ti}$ into the Ag layer and formation of $\mathrm{TiO}_{2-x}$ near the $\mathrm{Ag}$ grain boundaries could reduce absorption in the rear metal reflector and thus improve the optical properties of the metal contacting stack.

\section{Optical Simulation Results}

Following the procedure explained in Section III, the pyramid angle and thickness of the front dielectric layer was determined to be $53^{\circ}$ and $87 \mathrm{~nm}$, respectively. The Lambertian fraction for the reflectance at the planar rear surface was estimated to be 0.6, which gave best agreement between our simulations and measurements and is in the range obtained in other reports for alkaline-textured and then polished $\mathrm{Si}$ surfaces [28]. The thickness of the rear $\mathrm{SiN}_{x}$ - containing dielectric layer was determined to be $120 \mathrm{~nm}$ by ellipsometry. Using these simulation parameters and the measured optical constants of the novolac resin and the metal layers, the front-surface reflectance was simulated for the with resin and without resin precursors and compared with the experimentally measured reflectance values [see Fig. 6]. Although good agreement between the simulated and measured reflectance was achieved for the test structures with only $\mathrm{Ti}$ and only $\mathrm{Ag}$ over the resin, the simulated reflectance for the Ti/Ag stack was underestimated. This difference between the simulations and measurement for the Ti/Ag stack may result from the reactions that occur at the $\mathrm{Ti}$ and $\mathrm{Ag}$ interface with annealing as discussed above.

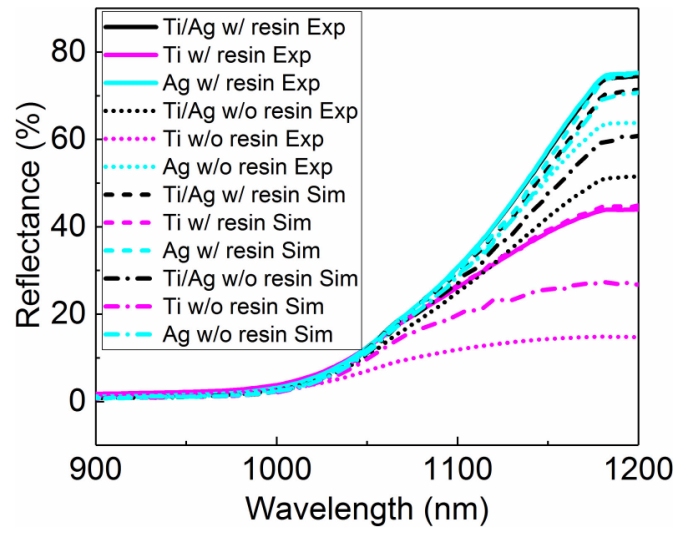

Fig. 6. Comparison of measured (after annealing) and simulated front-surface reflectance for $\mathrm{Ag}, \mathrm{Ti}$, and $\mathrm{Ti} / \mathrm{Ag}$ on IBC precursors with and without the novolac resin interlayer.

However, the simulations were not able to reproduce the low measured reflectances of the different metal contacting layers on the IBC precursors (i.e., no novolac resin interlayer). A possible reason for this discrepancy could be damage caused by sputtering to the dielectric layer, possibly resulting in changed optical constants for the dielectric layer, and also an increase of the roughness at the metal-dielectric interface. While these effects would also be expected to affect the metal-resin interface, the impact on the reflectance would be reduced due to the larger thickness of the resin layer compared with the dielectric layer and thus the enhanced decoupling of the metal from the rear surface. The mismatch between experiment and simulation is largest for the Ti without resist sample, i.e., the sample with highest parasitic absorption. It is therefore assumed that the mismatch was not caused by improved light trapping and thus improved band-to-band absorption in the Si wafer, but due to parasitic absorption at the rear surface. This discrepancy between simulation and measurements means that the actual benefit of introducing the resin interlayer is underestimated by our simulations.

A comparison of measured and simulated reflectance at $1100 \mathrm{~nm}$ is shown in Fig. 7, together with the simulated loss in the photogenerated current density $\left(J_{\text {gen }}\right)$ for the IBC solar cell. The wavelength of $1100 \mathrm{~nm}$ was used because at this wavelength, the absorptance of $\mathrm{Si}$ is so low that a significant fraction of photons pass through the solar cell without being absorbed and encounter the rear surface. From Fig. 7, it can be seen that higher reflectivity is correlated with lower parasitic absorption at the rear surface and thus a lower current loss for the device. The ray-tracing simulations suggest that the current loss of a Ti metallized IBC with a 120-nm-thick dielectric layer cell can be reduced by $0.61 \mathrm{~mA} / \mathrm{cm}^{2}$ by including a novolac resin interlayer to optically decouple the metal from the solar cell. However, considering the much lower measured than simulated reflection of the Ti metallized cell precursor, this value can only be regarded as lower limit and the actual loss is expected to be larger. Replacing the Ti metal layer in the simulations by a Ti/Ag metal stack with a 2-nm-thick Ti layer results in a reduction of the current loss by 0.44 or $0.94 \mathrm{~mA} / \mathrm{cm}^{2}$, for the case of IBC 


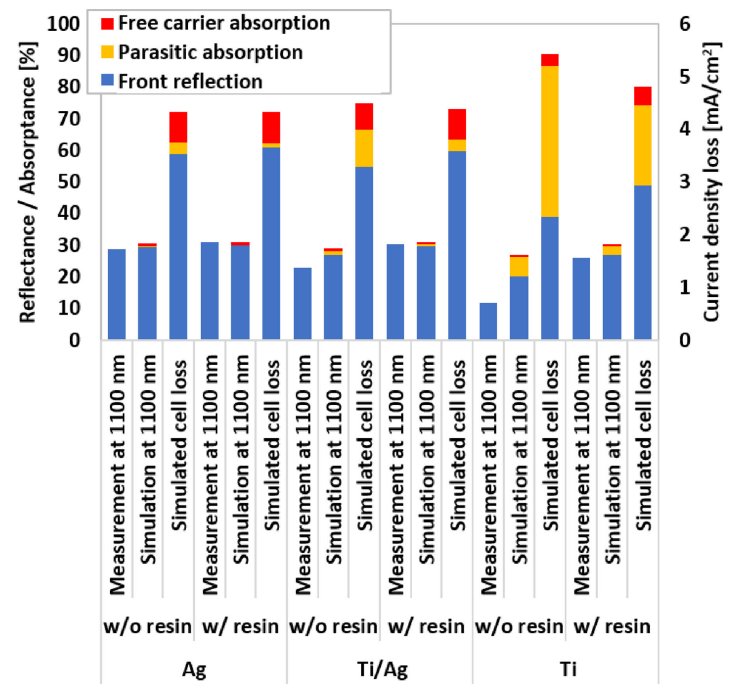

Fig. 7. Effect of an added novolac resin layer and different metal contacting layers on the measured and simulated reflection at $1100 \mathrm{~nm}$ and the $J_{\text {gen }}$ loss for the IBC cell precursors. (Numerical values can be found in Table SII in the Supplemental file).

cells with and without a resin layer, respectively. Again, these values are only lower limits and the actual advantage in terms of increased current is expected to be larger.

While it is well known that FCA in diffused regions at the rear surface of a solar cell can reduce the photogenerated current [29], Fig. 7 shows how significant this effect is compared with parasitic absorption losses of the rear metal. This highlights the importance of integrating FCA effects in the analysis of reflectance or quantum efficiency measurements of solar cells, especially in the cases of cells with diffused regions for metal contacting.

\section{CONCLUSION}

The optical advantages of an IBC metallization method, which employed an insulating novolac resin layer and a metal electrode comprising a sputtered Ti/Ag metal stack and plated $\mathrm{Cu}$, were identified. The use of a $2 \mathrm{~nm} \mathrm{Ti} / 200 \mathrm{~nm} \mathrm{Ag}$ sputtered metal stack with post annealing at $160{ }^{\circ} \mathrm{C}$ for $10 \mathrm{~min}$ on hot plate enabled $\rho_{c}$ values below $<1 \mathrm{~m} \Omega \cdot \mathrm{cm}^{2}$ for both $\mathrm{n}^{+}$and $\mathrm{p}^{+}$Si surfaces. Furthermore, the 900-1200 nm front-surface reflectance of the Ti/Ag stack was shown to be comparable to that of an Ag reflector largely due to the formation of a transparent $\mathrm{TiO}_{2-x}$ layer between the $\mathrm{Ti}$ and $\mathrm{Ag}$ during annealing in air.

In addition to allowing greater electrode coverage on the rear surface, the resin interlayer was able to reduce the optical losses associated with parasitic absorption in the rear metal electrode. For a lossy $\mathrm{Ti}$ contact metal layer, the addition of the resin interlayer was predicted to enhance the photogenerated current density by at least $0.61 \mathrm{~mA} / \mathrm{cm}^{2}$. By replacing the Ti contact layer with a Ti/Ag stack, a further gain of $0.44 \mathrm{~mA} / \mathrm{cm}^{2}$ was suggested by the ray-tracing simulations, which is very close to the increment of $0.49 \mathrm{~mA} / \mathrm{cm}^{2}$ made possible through the use of an $\mathrm{Ag}$ reflector. This demonstrates that the use of an annealed $\mathrm{Ti} / \mathrm{Ag}$ contact stack results in very similar optical performance to that of an Ag reflector, while offering the additional benefit of low contact resistivities to both the $\mathrm{n}^{+}$and $\mathrm{p}^{+}$Si regions of the diffused IBC cells. The rear-surface optical analysis presented in this study highlighted the need to include FCA in analyses of rear optical performance, especially for the case of diffused junction solar cells.

\section{ACKNOWLEDGMENT}

Responsibility for the views, information, or advice expressed herein is not accepted by the Australian Government. The authors would like to acknowledge the facilities, and the scientific and technical assistance of the Mark Wainwright Analytical Centre, the University of New South Wales (UNSW). The authors also would like to acknowledge the use of the facilities and the assistance of Dr. D. Mitchell at the UOW Electron Microscopy Centre. This work was performed in part at the UNSW node of the Australian National Fabrication Facility.

\section{REFERENCES}

[1] K. Yoshikawa et al., "Silicon heterojunction solar cell with interdigitated back contacts for a photoconversion efficiency over 26\%," Nature Energy, vol. 2, Mar. 2017, Art. no. 17032.

[2] D. D. Smith et al., "Silicon solar cells with total area efficiency above 25\%," in Proc. IEEE 43rd Photovolt. Spec. Conf., 2016, pp. 3351-3355.

[3] Z. Li et al., "Patterning for plated heterojunction cells," Energy Procedia, vol. 67, pp. 76-83, Apr. 2015.

[4] Z. Li et al., "Electrical and optical analysis of polymer rear insulation layers for back contact cells," Energy Procedia, vol. 77, pp. 744-751, Aug. 2015.

[5] U. Römer et al., "Decoupling the metal layer of back contact solar cellsoptical and electrical benefits," Energy Procedia, vol. 124, pp. 907-913, Sep. 2017.

[6] P. Verlinden, R. Swanson, R. Sinton, D. Kane, and M. Cullough, "Multilevel metallisation for large area point-contact solar cells," in Proc. 8th Eur. Photovolt. Sol. Energy Conf. Exhib, Florence, Italy, 1988, pp. 1466-1471.

[7] C. Reichel, M. Reusch, F. Granek, and M. Hermle, "Decoupling charge carrier collection and metallization geometry of back-contacted backjunction silicon solar cells by using insulating thin films," in Proc. 35th IEEE Photovolt. Spec. Conf., 2010, pp. 001034-001038.

[8] H. Schulte-Huxel et al., "Two-level metallization and module integration of point-contacted solar cells," Energy Procedia, vol. 55, pp. 361-368, 2014.

[9] J. Robbelein et al., "Passivation layers for large area interdigitated back junction cells and their electrical isolation properties," in Proc. 26th Eur. Photovolt. Sol. Energy Conf. Exhib., 2011, pp. 1008-1013.

[10] Z. C. Holman et al., "Infrared light management in high-efficiency silicon heterojunction and rear-passivated solar cells," J. Appl. Phys., vol. 113, 2013, Art. no. 013107.

[11] Z. C. Holman, S. De Wolf, and C. Ballif, "Improving metal reflectors by suppressing surface plasmon polaritons: A priori calculation of the internal reflectance of a solar cell," Light, Sci. Appl., vol. 2, Jul. 2013, Art. no. e106.

[12] Z. C. Holman et al., "Parasitic absorption in the rear reflector of a silicon solar cell: Simulation and measurement of the sub-bandgap reflectance for common dielectric/metal reflectors," Sol. Energy Mater. Sol. Cells, Part A, vol. 120, pp. 426-430, Jan. 2014.

[13] M. A. Green, P. Basore, N. Chang, D. Clugston, R. Egan et al., "Crystalline silicon on glass (CSG) thin-film solar cell modules," Sol. Energy, vol. 77, pp. 857-863, 2004.

[14] Z. Li and A. Lennon, "Patterned masking using polymers: insights and developments from silicon photovoltaics," Int. Mater. Rev., vol. 61, pp. 416$435,2016$.

[15] Z. Li et al., "Patterning and metallization of silicon solar cells by inkjetprinted functional ink on a photoresist layer," in Proc. IEEE 40th Photovolt. Spec. Conf., 2014, pp. 2499-2501.

[16] G. Xu et al., "Large-area (6 inch) screen-printed IBC solar cells with efficiency above $24.1 \%$ without passivated contacts," in Proc. 33rd Eur. Photovolt. Sol. Energy Conf. Exhib., Amsterdam, the Netherlands, 2017, pp. $428-430$. 
[17] J. P. Gambino and E. G. Colgan, "Silicides and ohmic contacts," Mater. Chem. Phys., vol. 52, pp. 99-146, Feb. 1998.

[18] R. B. Campbell and A. Rohatgi, "Investigation of contact metallization systems for solar cells," J. Electrochem. Soc., vol. 127, pp. 2702-2704, Dec. 1980.

[19] V. E. Lowe and A. C. Day, "High-temperature-stable contact metallization for silicon solar cells," IEEE Trans. Electron Devices, vol. 31, no. 5, pp. 626-629, May 1984.

[20] A. Mette, "New concepts for front side metallization of industrial silicon solar cells," Ph.D. thesis, Univ. Freiburg, Freiburg, Germany, 2007.

[21] R. Couderc, M. Amara, and M. Lemiti, "Improvement of back surface metallization in a silicon interdigitated back contacts solar cell," Energy Procedia, vol. 38, pp. 684-690, Jan. 2013.

[22] PV Lighthouse: SunSolve, 2014. [Online]. Available: https://www. pvlighthouse.com.au/sunsolve. Accessed on: Feb. 25, 2018.

[23] K. R. McIntosh et al., "Quantifying the optical losses in back-contact solar cells," in Proc. IEEE 40th Photovolt. Spec. Conf., 2014, pp. 0115-0123.

[24] S. C. Baker-Finch, K. R. McIntosh, D. Yan, K. C. Fong, and T. C. Kho, "Near-infrared free carrier absorption in heavily doped silicon," J. Appl. Phys., vol. 116, 2014, Art. no. 063106.
[25] C. Schinke et al., "Uncertainty analysis for the coefficient of band-to-band absorption of crystalline silicon," AIP Adv., vol. 5, 2015, Art. no. 067168.

[26] R. Butz, G. Rubloff, and P. Ho, "Chemical bonding and reactions at Ti/S and Ti/oxygen/Si interfaces," J. Vacuum Sci. Technol. A, Vacuum, Surfaces, Films, vol. 1, pp. 771-775, Dec. 1983.

[27] R. Schmiedl et al., "Oxygen diffusion through thin Pt films on Si (100)," Appl. Phys. A, vol. 62, pp. 223-230, Mar. 1996.

[28] C. Kranz et al., "Impact of the rear surface roughness on industrial-type PERC solar cells," in Proc. 27th Eur. Photovolt. Sol. Energy Conf. Exhib., 2012, pp. 557-560.

[29] M. Rüdiger, J. Greulich, A. Richter, and M. Hermle, "Parameterization of free carrier absorption in highly doped silicon for solar cells," IEEE Trans. Electron Devices, vol. 60, no. 7, pp. 2156-2163, Jul. 2013.

Authors' photographs and biographies not available at the time of publication. 